\title{
Vocabulary is important for some, but not all reading skills
}

Article

Accepted Version

Ricketts, J., Nation, K. and Bishop, D. V. (2007) Vocabulary is important for some, but not all reading skills. Scientific Studies of Reading, 11 (3). pp. 235-257. ISSN 1088-8438 doi: https://doi.org/10.1080/10888430701344306 Available at https://centaur.reading.ac.uk/27869/

It is advisable to refer to the publisher's version if you intend to cite from the work. See Guidance on citing.

To link to this article DOI: http://dx.doi.org/10.1080/10888430701344306

Publisher: Routledge

All outputs in CentAUR are protected by Intellectual Property Rights law, including copyright law. Copyright and IPR is retained by the creators or other copyright holders. Terms and conditions for use of this material are defined in the End User Agreement.

\section{www.reading.ac.uk/centaur}

\section{CentAUR}

Central Archive at the University of Reading

Reading's research outputs online 
Vocabulary is important for some, but not all reading skills

Jessie Ricketts, Kate Nation and DVM Bishop

University of Oxford

In press for 2007: Scientific Studies of Reading

Running Head: Vocabulary is important for

Correspondence:

Jessie Ricketts

Department of Experimental Psychology

University of Oxford

South Parks Road

Oxford, OX1 3UD, UK

Email: jessie.ricketts@psy.ox.ac.uk 


\begin{abstract}
Although there is evidence for a close link between the development of oral vocabulary and reading comprehension, less clear is whether oral vocabulary skills relate to the development of word-level reading skills. This study investigated vocabulary and literacy in 81 children of 8-10 years. In regression analyses, vocabulary accounted for unique variance in exception word reading and reading comprehension, but not text reading accuracy, decoding and regular word reading. Consistent with these data, children with poor reading comprehension exhibited oral vocabulary weaknesses and read fewer exception words correctly. These findings demonstrate that oral vocabulary is associated with some, but not all reading skills. Results are discussed in terms of current models of reading development.
\end{abstract}


Vocabulary is important for some, but not all reading skills

It is well accepted that learning to read is intimately connected to children's underlying oral language skills. Most research has focused on the vital role that phonological skills play in the development of reading, while the potential importance of other aspects of oral language skill has been downplayed. In this paper, we consider the role of oral vocabulary in reading development. Specifically, we sought to investigate whether individual differences in vocabulary development relate to some, but not all of the following component reading skills: reading comprehension, text reading accuracy, recognizing words and deciphering nonwords.

\section{Oral vocabulary and reading skills}

It seems difficult to dismiss the idea that vocabulary plays an important role in the development of reading comprehension - the ability to understand connected text. Logically, children will need to know the words that make up a written text to fully understand it. Further, it seems likely that the relationship between vocabulary and reading comprehension will be reciprocal across development, as reading provides an opportunity to learn new word meanings (e.g., Beck, Perfetti, \& McKeown, 1982). Consistent with this, children with poor reading comprehension tend to show relatively low levels of vocabulary knowledge (Nation, Clarke, Marshall, \& Durand, 2004) and they are poor at using textual support to infer the meanings of new words (Cain, Oakhill, \& Lemmon, 2004).

It is less clear, however, whether oral vocabulary skills play an important role in the development of word recognition and reading accuracy. The Lexical Restructuring Model proposed by Metsala, Walley and colleagues specifies a relationship between vocabulary and word reading development, albeit an indirect one (e.g., Walley, Metsala, \& Garlock, 2003). According to this account, oral vocabulary growth leads to the development of increasingly 
well-specified phonological representations, and it is these more fine grained phonological representations that promote reading development.

A more direct role for oral language skills is conferred by connectionist models of reading development. The triangle model (e.g., Harm \& Seidenberg, 2004; Plaut, McClelland, Seidenberg, \& Patterson, 1996; see Figure 1) and approaches built upon it (e.g., Bishop \& Snowling, 2004) provide a theoretical framework for considering the contribution of language skills other than phonology to word reading development. Early versions of the model focused exclusively on connections between orthography and phonology (Seidenberg \& McClelland, 1989). However, more recent incarnations have emphasized the contribution of semantic knowledge - knowledge of word meanings - to word recognition and its development. To understand why this is the case, it is necessary to describe the model in some detail. It comprises a phonological pathway consisting of connections between representations of phonological and orthographic information. The other (semantic) pathway consists of mappings between semantic, phonological and orthographic representations. Although in the triangle model both pathways and all types of representation are involved in the computation of all words, Plaut et al. and Harm and Seidenberg found, as the model learned to recognize a corpus of printed words, that the balance between the two pathways changed - a process they termed division of labor. Early in training, the models' resources were devoted to establishing direct connections between orthography and phonology (the phonological pathway), akin to the early stages of learning to read. However, later in training, the computational model came to depend increasingly on mappings from orthography to phonology via semantics (the semantic pathway). This was particularly the case for those words with inconsistent orthographic-phonological mappings, exception words such as break and foot. 
Why should this be the case? In the early phases of reading development, children must establish a system of mappings between letters and sounds and it is well-accepted that this alphabetic or decoding system is underpinned by phonological skills in the oral domain (e.g., Brady \& Shankweiler, 1991; Byrne, 1998; Goswami \& Bryant, 1990). To become an accurate and efficient reader of the English language, however, a child must acquire a flexible word recognition system that embodies knowledge of both the regularities and the irregularities of the English orthography. A child must be able to read words for which decoding skills are not sufficient, such as exception words, wherein the mappings between spelling and sound patterns are inconsistent. For example, the word break could potentially be pronounced to rhyme with steak or freak; and a direct spelling-sound translation of the word yacht, would lead to a mispronunciation. In the triangle model all types of representation are involved in the computation of all words regardless of their consistency. However, simulations have shown that with training the semantic pathway becomes more important - i.e., shows a greater behavioral effect - for the computation of words with inconsistent orthographic-phonological mappings (Harm \& Seidenberg, 2004; Plaut et al., 1996).

Thus, a clear prediction stemming from the triangle model is that individual differences in the semantic pathway should relate to individual differences in word reading proficiency, more strongly so for words with less consistent spelling-sound mappings. The nature of semantic representation is not well-specified in current versions of the triangle model although it is reasonable to suppose that a child's oral vocabulary knowledge is a suitable index of semantic knowledge. Consistent with this prediction from the triangle model, Keenan and Betjemann (in press) suggested that semantic knowledge could provide compensatory support for exception word reading because in this case phonological- 
orthographic representations are weak. Some preliminary evidence for a relationship between semantic knowledge (vocabulary) and exception words was provided by Bowey (2001).

Nation and Snowling (2004) provided additional support for the prediction that oral vocabulary skills are related to exception word reading. They assessed the reading and language abilities of a group of typically-developing children in a longitudinal study. Nation and Snowling found that performance on an expressive vocabulary task at age 8 years accounted for variance in exception word reading at age 13 years, even after controlling for individual differences in decoding (nonword reading). Although these findings are consistent with the predictions of the triangle model, they are difficult to interpret for a number of reasons. First, vocabulary was assessed at 8 years, and exception word reading was assessed at 13 years. Because exception word reading was not assessed at 8 years, there was no control for earlier exception word reading. Therefore, it was not clear whether vocabulary contributed to later exception word reading because of an earlier association with exception word reading, or whether the variance it explained was independent of this autoregression effect. A finding that vocabulary can still account for variance in later exception word reading after controlling for earlier exception word reading would provide strong evidence for an independent role of vocabulary in word recognition skills. Second, although there was a relationship between semantic skills and exception word reading, the specificity of this relationship is impossible to assess as they failed to measure reading of words that have more consistent spelling-sound mappings. As the triangle model posits a particular role for semantics when reading exception words, it is important to test this behaviorally by assessing how vocabulary relates to the reading of both exception words and non-exception words using parallel regression analyses. 


\section{Children with poor reading comprehension}

Another source of evidence supporting the view that vocabulary plays a role in reading development comes from studies of children with reading comprehension impairments. Poor comprehenders make up approximately $10 \%$ of $7-11$ year olds (e.g., Nation, 2005) and are defined as children who have at least age-appropriate reading accuracy skills, but have specific difficulty with reading comprehension. In terms of oral language, poor comprehenders have strong phonological skills but show weaknesses in other areas of language such as listening comprehension and vocabulary (Catts, Adlof, \& Weismer, 2006; Nation et al., 2004). In addition to their problems with reading comprehension and associated problems with vocabulary (Cain, Oakhill, \& Bryant, 2004), there is evidence to suggest that poor comprehenders have subtle weaknesses in reading words that have inconsistent spellingsound patterns. For example, Nation and Snowling (1998) found that despite poor comprehenders being tightly matched to skilled comprehenders for decoding ability (nonword reading), they were significantly less accurate at reading exception words. Byrne et al. (1992) also observed the co-occurrence of difficulties in reading comprehension and exception word reading. While Byrne et al. did not provide a mechanistic account of this association, Nation and Snowling explained this observation with reference to the triangle model. They argued that weaknesses in vocabulary knowledge constrained the utility of the semantic pathway, leading to weaknesses in reading exception words, despite proficiency in reading nonwords and words with more consistent mappings. Thus, data from poor comprehenders are intriguing as they demonstrate that weaknesses in three domains, namely reading comprehension, vocabulary and exception word reading, tend to co-occur.

Although Nation and Snowling attributed deficits in exception word reading to deficiencies in the semantic pathway, underpinned by relative weaknesses in oral vocabulary, there are of course alternative explanations. In the triangle model, orthographic 
representations form part of the semantic pathway. According to some theorists, differences in orthographic representation or the mapping between orthographic units and other units may lead to difficulties with exception word reading (Harm \& Seidenberg, 1999; Manis et al., 1996). Arguably therefore, deficits in exception word reading in poor comprehenders may be a consequence of orthographic weaknesses, rather than semantic weaknesses. Unfortunately, testing this prediction is difficult as we lack direct measures of orthographic skill, independent from the word recognition process itself. For example, in an orthographic choice task, children are presented with two plausible spellings for a word and are asked to select the correct spelling (e.g. assure/ashure). As noted by Vellutino, Scanlon and Tanzman (1994), this task taps children's word specific representations and therefore, rather than the task being a suitable predictor of skilled word recognition, it is a measure of word recognition itself. Print exposure is also considered to be a measure of orthographic skill. Consistent with this view, it does predict variance in word recognition above and beyond the contribution of alphabetic and phonological skills (Cunningham \& Stanovich, 1993). Once again however, it is difficult to ascertain the extent to which print exposure should be considered a predictor of word reading success, rather than the outcome of word reading success (see Castles \& Nation, 2006, for fuller discussion).

Despite the difficulty of interpreting exactly what measures of orthographic processing are tapping, it is the case that performance on both orthographic choice (e.g. Manis, Seidenberg, Doi, McBride-Chang, \& Petersen, 1996) and print exposure (Castles et al., 1999; Griffiths \& Snowling, 2002) tasks predict exception word reading. These relationships have not been explored in poor comprehenders - children who have welldeveloped word-level decoding skills underpinned by strong phonological skills. Some preliminary data suggest that poor comprehenders have less reading experience than control children (Cain, 1994; cited in Oakhill \& Yuill, 1996) but this has yet to be replicated. 
Therefore, we decided to investigate orthographic choice and print exposure in poor comprehenders, and ask whether performance on these tasks was associated with their exception word reading.

\section{The current study}

To date, there is evidence that individual differences in oral vocabulary skills play a role in reading comprehension development; there is also evidence to suggest that vocabulary might be important for word reading, especially for words that are inconsistent (exception words). However, many questions have not been addressed. There were two broad aims of the current study. The first aim was to assess which reading skills are predicted by oral vocabulary. To address this aim, vocabulary and reading skills were assessed in a large sample of children aged 8-9 years. Vocabulary was then investigated as a predictor of reading comprehension, decoding and word recognition skills. To extend Nation and Snowling (2004) we assessed regular word reading so that predictors of exception word and regular word reading could be compared. We expected that vocabulary would make independent contributions to two aspects of reading in particular: reading comprehension and exception word reading.

The second aim was to replicate and explore further the link between oral vocabulary and exception word reading in children with poor reading comprehension. Poor and skilled comprehenders were selected from the larger sample and were seen at two time points: when they were aged 8-9 years, and approximately 10 months later. This design allowed us to address three issues. First, we asked whether the finding that poor comprehenders exhibit both oral vocabulary and exception word reading deficits (Nation \& Snowling, 1998) replicates. Second, we investigated concurrent and longitudinal relationships between vocabulary and different aspects of reading ability. Importantly, we measured exception word reading at two time points, allowing us to assess whether vocabulary predicts later exception 
word reading once earlier exception word reading has been accounted for. We also measured phonological awareness, as phonological awareness is known to be a very powerful predictor of word recognition skills (e.g. Goswami \& Bryant, 1990). This allowed us to ask whether this measure of oral language skill predicts exception word reading more specifically. Third, we assessed orthographic knowledge and experience of print in poor comprehenders to see if these variables interact with the oral vocabulary and reading skills of poor comprehenders. In particular, we sought to determine whether these variables, as well as oral vocabulary, are associated with exception word reading.

\section{Method}

\section{Participants}

\section{Whole sample}

Eighty-three children attending schools serving socially mixed catchment areas in Middlesex and Oxford took part in this study (Table 1). The children were between 8 years and 8 months and 9 years and 9 months of age. None spoke English as a second language or had any recognized special educational needs. Two children were excluded due to possible language impairment (one child awaiting clinical assessment) and uncorrected eyesight while reading (one child forgot to wear glasses). This resulted in a sample of 81 children (58 female and 23 male).

\section{Poor comprehenders versus skilled comprehenders}

Time 1. Fifteen poor comprehenders and 15 skilled comprehenders were selected from the above sample according to the following criteria (see Materials section for details of selection measures). Children (11 female and 4 male) scoring at least one SD below the population norm (i.e., standard score $<85$ ) on the reading comprehension subtest of the Neale Analysis of Reading Ability-II (Neale, 1997) were classified as poor comprehenders. Fifteen 
children (11 female and 4 male) with more skilled comprehension (reading comprehension scores $>95$ ) were matched to poor comprehenders for age, nonverbal ability (Wechsler Abbreviated Scale of Intelligence; Wechsler, 1999) and decoding level (Test of Word Reading Efficiency; Torgesen, Wagner, \& Rashotte, 1999). Performance of the two groups of children on the selection measures is summarized in the upper portion of Table 2.

Time 2. The poor and skilled comprehenders identified at time 1 were followed up approximately 10 months later (Table 3 ).

\section{Materials and Procedure}

The whole sample of children completed measures of reading, language and general cognitive ability in one session lasting approximately 45 minutes to one hour. Tasks were administered to all children in the same order. These tests are referred to as time 1 in the list below. Poor and skilled comprehenders completed additional measures at time 2, administered over three sessions of approximately half an hour each.

\section{Nonverbal reasoning skills (time 1)}

Nonverbal reasoning was measured at time 1 using the Matrix Reasoning subtest of the Wechsler Abbreviated Scale of Intelligence (WASI; Wechsler, 1999). This subtest assesses nonverbal reasoning using a pattern completion task. The WASI provides norms for individuals aged 6-89 years.

\section{Reading skills}

Decoding ability (time 1 and time 2). Decoding was assessed using the Phonemic Decoding component of the Test of Word Reading Efficiency (TOWRE; Torgesen et al., 1999). In this test children are asked to read a list of nonwords of increasing length and difficulty as quickly as they can. Efficiency is indexed by the number of nonwords decoded 
correctly in 45 seconds. The test provides norms for individuals aged 6-24 years. At time 1 form A of the test was administered, whereas its parallel (form B) was administered at time 2.

Text reading accuracy and reading comprehension (time 1). Text reading was assessed using the Neale Analysis of Reading Ability-II (NARA-II; Neale, 1997). In the NARA-II children read aloud passages of connected text and then answer comprehension questions relating to each passage. Some questions can be answered with reference to verbatim memory while others require inferences to be made (Bowyer-Crane \& Snowling, 2005). This yields a measure of text reading accuracy and a measure of reading comprehension. The test provides norms for children aged 6-12 years.

Component reading skills (time 1 and 2). At time 1 lists of 30 exception words, 30 regular words and 30 nonwords from Coltheart and Leahy (1996) were used. The three lists were matched on number of letters and number of syllables. The regular and exception words were also matched for word frequency. It is unclear from Coltheart and Leahy (1996) how lists were matched for frequency; however we confirmed that the lists were matched for frequency in terms of printed frequency in children's literature in the UK (Children's Printed Word Database; Masterson, Dixon, \& Stuart, 2002). Children were presented with each list printed on a sheet of A4 card, Comic Sans MS font, size 18. Order of presentation of the lists was fully counterbalanced so that equal numbers of children received the lists in each of the three possible orders (regular-exception-nonword, exception-nonword-regular, and nonwordregular-exception). The reliability ratings (Chronbach's $\alpha$ ) for nonword, regular word and exception word lists were $0.88,0.76$ and 0.80 respectively $^{1}$. A proportion correct score was calculated for each child.

At time 2 component reading skills were assessed by asking children to read a block of 20 nonwords and a block of 70 words $^{2}$. Blocks (nonwords vs. words) and items within blocks were presented in a random order. Each word or nonword was presented one at a time 
in the middle of the computer screen. Children read the letter string aloud and accuracy was scored by the experimenter. Items in the word block comprised 30 exception words. The remaining words varied in consistency and were included to detract attention away from the exception items, so that children would not be immediately alerted to the fact that they were reading 'strange' words. Reliability ratings (Chronbach's $\alpha$ ) for nonword and exception word lists were 0.77 and 0.80 respectively. A proportion correct score was calculated for each child.

Reading-related skills

Vocabulary ability (time 1 and 2). At time 1 vocabulary was measured using the Vocabulary subtest of the WASI (Wechsler, 1999). This subtest is a measure of expressive vocabulary in which children are asked to verbally define words. The WASI provides norms for individuals aged 6-89 years. At time 2 vocabulary was assessed using the Multiple Contexts subtest of the Test of Word Knowledge (TOWK, Wiig \& Secord, 1992). This subtest is a measure of expressive vocabulary in which children are presented with a set of words with multiple meanings (e.g., bat) and are required to provide two distinct definitions for each word (e.g., the thing you hit a ball with, an animal that flies). The TOWK provides norms for children aged 5-17 years.

Phonological skills (time 2). Phonological skills were assessed using a phoneme deletion task (see McDougall, Hulme, Ellis, \& Monk, 1994 for materials). Children were presented with a nonword and required to tell the experimenter which word would remain if they took away a particular sound (e.g., bice $\rightarrow$ ice, stip $\rightarrow$ sip, cloof $\rightarrow$ clue). For example if presented with "bice" and asked to take away the sound /b/ they would be expected to respond "ice". Children were required to delete sounds from the beginning, middle and end of nonwords. Most phonemes to be deleted were from consonant clusters. Two practice trials were administered to ensure that children understood the demands of the task; then test items 
were administered in order of difficulty. The maximum score was 22 and the reliability rating (Chronbach's $\alpha$ ) for this measure was $0.55^{3}$.

Orthographic knowledge (time 2). Orthographic knowledge was assessed using a task adapted from the work of Olson and colleagues (Olson, Forsberg, Wise, \& Rack, 1994). Children were presented with two letter strings on a computer screen (e.g., assure/ashure, explain/explane, pavement/pavemant). Both letter strings in each pair could be pronounced in the same way, but only one letter string was the correct spelling for a word in the English language. Children were asked to press one of two computer keys to indicate which item they thought was the correct spelling. Each child was given a score of the number of correct items out of a maximum of 40 . The reliability rating (Chronbach's $\alpha$ ) for this measure was 0.86 .

Print exposure (time 2). An author recognition task (ART) was developed to assess print exposure. To develop the test, a list of popular children's authors and foil names was presented to a class of children approximately the same age as the children included in this study. Each name was presented one at a time and children were asked to put a tick next to a name if they thought he or she was a children's author. The 25 most commonly recognized targets (authors) were included in the task. Also, the foils that were least commonly selected (falsely recognized) were included. The resulting set of 50 items ${ }^{4}$ was presented to each participant in a single random order on one sheet of paper. Children were asked to read the names and put a tick next to any that they thought were authors. The score (cf. Cunningham, Perry, \& Stanovich, 2001) was the proportion of targets correctly selected minus the proportion of foils incorrectly selected. The reliability rating (Chronbach's $\alpha$ ) was 0.70 for targets. 


\section{Results}

The relationship between vocabulary and reading in the whole sample

From Table 1, it is clear that children in the full sample performed close to the population mean on all standardized measures. Correlations were computed to assess the relationship between reading and reading related measures (Table 4). As anticipated most variables were significantly correlated. However, chronological age was only correlated with two variables, exception word reading and text reading accuracy. Also, reading comprehension did not correlate with either measure of nonword reading.

A set of hierarchical regressions were conducted to assess 1) whether vocabulary predicts reading comprehension and text reading accuracy, even when nonword and word reading skills have been accounted for, 2) whether vocabulary predicts exception word reading, once nonword and regular word reading are accounted for and 3) whether vocabulary predicts measures of nonword reading and regular word reading after controlling for exception word reading. Raw TOWRE phonemic decoding and nonword reading (time 1) scores were highly correlated $(r=.77)$. Thus they were converted into $z$ scores and summed to form a composite decoding score reflecting both nonword reading accuracy and efficiency.

Table 5 summarizes hierarchical regression analyses predicting reading comprehension and text reading accuracy. Once chronological age, nonverbal reasoning and decoding had been entered into the models (steps 1, 2 and 3), regular word reading (step 4) and then exception word reading (step 5) accounted for significant additional variance in both reading comprehension and text reading. After controlling for all of these variables, oral vocabulary accounted for a significant $17.8 \%$ of the variance in reading comprehension. However, it failed to account for additional variance in text reading accuracy. When vocabulary was entered into the models at step 5, it accounted for significant additional 
variance in both reading comprehension and text reading accuracy. At step 6, exception word reading accounted for significant additional variance in text reading accuracy but not reading comprehension. In sum, at the final step vocabulary accounted for unique variance in reading comprehension but not text reading accuracy whereas exception word reading accounted for unique variance in text reading accuracy but not reading comprehension.

A second set of hierarchical regressions was conducted to compare the contribution of vocabulary skills to other measures of component reading skill to test the specific prediction that vocabulary is important for the reading of exception words. Three parallel analyses are reported in Table 6, predicting exception word reading, regular word reading and nonword reading respectively. In line with our predictions, vocabulary predicted exception word reading once other component reading skills were taken into account, but it was not associated with regular word or nonword reading.

\section{Poor versus skilled comprehenders at time 1}

The lower portion of Table 2 shows the performance of poor and skilled comprehenders on the time 1 measures. Poor comprehenders exhibited significantly weaker vocabulary skills $\left(F(1,28)=25.25, p<.001, \eta^{2}=.48\right)$ than skilled comprehenders. A $2 \times 3$ analysis of variance with comprehension group (poor vs. skilled) as an independent samples factor, and word type (regular vs. exception vs. nonword) as a related samples factor was conducted across both subjects $\left(F_{s}\right)$ and items $\left(F_{i}\right)$. There was a trend for a main effect of comprehension group but this was only significant in the by-items analysis $\left(F_{s}(1,28)=3.66\right.$, $\left.p=.07, \eta^{2}=.12 ; F_{i}(1,87)=30.98, p<.01, \eta^{2}=.26\right)$. There was a significant main effect of word type $\left(F_{s}(2,56)=39.44, p<.001, \eta^{2}=.59 ; F_{i}(1,87)=5.88, p<.01, \eta^{2}=.12\right)$ reflecting the relative ease of regular word reading. As predicted, the word type x comprehension group interaction was also significant $\left(F_{s}(2,56)=3.78, p<.05, \eta^{2}=.12 ; F_{i}(2,87)=8.82, p<.01, \eta^{2}\right.$ $=.17$ ). Planned comparisons (Table 2) demonstrated a significant difference between groups 
on exception word reading, but not on regular word or nonword reading. Consistent with previous work, these findings demonstrate that poor comprehenders show relative weaknesses in both oral vocabulary and exception word reading.

\section{Poor versus skilled comprehenders at time 2}

Poor and skilled comprehenders were followed up approximately 10 months later at time 2 . The focus at time 2 was to further investigate factors related to reading comprehension and exception word reading by collecting longitudinal data and including some additional variables not measured at time 1: phonological awareness (phoneme deletion), orthographic knowledge (orthographic choice) and print exposure (ART). Performance of groups on time 2 measures is summarized in Table 3.

First, we compared vocabulary and exception word reading in the poor and skilled comprehenders approximately10 months later. Replicating our findings from time 1, Table 3 shows that the same sample of poor comprehenders exhibited lower scores on both vocabulary $\left(F_{s}(1,28)=18.03, p<.001, \eta^{2}=.39\right)$ and exception word reading $\left(F_{s}(1,28)=\right.$ $\left.10.11, p<.01, \eta^{2}=.27\right)$. As vocabulary was measured using a standardized test, analysis by items could not be conducted. For exception word reading the effect of group was also significant by items $\left(F_{i}(2,56)=18.68, p<.001, \eta^{2}=.39\right)$. Groups did not differ on either measure of nonword reading $(F s<1)$; nor did the groups differ in terms of phoneme deletion or print exposure $(F s<1)$. For orthographic choice, there was no group difference by subjects, $\left(F_{s}(1,28)=1.85, p>.05, \eta^{2}=.06\right)$ although the effect was significant across items $\left(F_{i}(1,28)=20.39, p<0.01, \eta^{2}=.36\right)$.

Our final set of analyses explored the relationship between time 1 and time 2 measures. Hierarchical regressions predicting time 2 exception word reading from vocabulary are presented in Table 7. Predictor variables were kept to a minimum due to our limited sample size $(\mathrm{n}=30)$. Therefore chronological age and general cognitive ability scores (WASI 
matrices collected at time 1) were not included in the analyses ${ }^{5}$. As time 1 and time 2 decoding composites were highly correlated (all $p \mathrm{~s}<.01$ ), they were summed together to form an overall decoding composite. When the decoding composite was entered into the regression at step 1, it accounted for a significant $18.8 \%$ of the variance in time 2 exception word reading. When entered at step 2 , time 1 and 2 measures of oral vocabulary accounted for a further $25.7 \%$ and $43.9 \%$ of the variance respectively. To control for autoregressor effects a second set of analyses was conducted including earlier exception word reading at step 2. Even after controlling for the powerful effect of earlier exception word reading, the effect of time 1 vocabulary approached but did not quite reach significance $(p=0.06)$.

A second set of hierarchical regressions was conducted to address the issue of whether variables other than vocabulary predict time 2 exception word reading. These analyses are summarized in Table 8 . Neither phoneme deletion nor print exposure accounted for additional variance in time 2 exception word reading after controlling for decoding skills. In contrast, orthographic choice predicted significant independent variance (17.1\%). However, after controlling for the autoregressor effect (the effect of earlier exception word reading), the effect of orthographic choice was not significant.

\section{Discussion}

The first aim of this study was to investigate which reading skills are related to oral vocabulary. In a large sample of children aged 8-9 years, we found that oral vocabulary skills predicted concurrent reading comprehension and exception word reading but not text reading accuracy, nonword reading or regular word reading. We extended Nation and Snowling's findings (2004) by showing that vocabulary predicts some word recognition skills but not others. By including separate measures of regular and exception word reading, we could show that vocabulary was uniquely associated with exception word reading but not regular 
word reading. Also, regular word reading accounted for independent variance in exception word reading - once age, nonverbal skills and decoding had been controlled - and vice versa. Overall, our findings are consistent with the idea that individual differences in oral vocabulary play a role in some, but not all reading skills.

Poor comprehenders provide a useful population for investigating links between reading comprehension, exception word reading and vocabulary as they have been shown to have deficits in all three areas (Nation \& Snowling, 1998). We replicated this finding by selecting poor and skilled comprehenders from our larger sample. Poor comprehenders exhibited vocabulary weaknesses, and read fewer exception words in comparison to skilled comprehenders at both time 1 and time 2. In the sample of poor and skilled comprehenders, vocabulary was concurrently and longitudinally associated with exception word reading, even when decoding skill was controlled. We measured exception word reading at time 1 and time 2 so that the autoregressor effects of earlier exception word reading could be taken into account. Even after the powerful effects of earlier exception word reading had been controlled, the relationship between earlier vocabulary and later exception word reading approached significance. As this value did not quite reach significance, an important aim of future research would be to investigate this issue with a larger sample of children. Also, it would be of interest to use an unselected group of children to ensure that this finding generalizes to a more representative sample of the population.

Poor comprehenders did not differ from skilled comprehenders on a measure of phonological processing skill. This finding replicates many previous studies (e.g., Cain, Oakhill, \& Bryant, 2000; Catts et al., 2006; Nation \& Snowling, 1998). In addition, groups did not differ on tasks tapping orthographic knowledge and print exposure. As mentioned in the introduction, it is not entirely clear what these measures of orthographic processing reflect. Nonetheless, to our knowledge this is the first systematic investigation of 
orthographic knowledge in poor comprehenders. One unpublished study has investigated reading experience in this population: Cain (1994, cited in Oakhill \& Yuill, 1996) reported preliminary data from a questionnaire on home reading habits suggesting that poor comprehenders may have had less exposure to stories than more skilled comprehenders. In our study however, there was no group difference in print exposure, as measured by an Author Recognition Test. Therefore, while print exposure may explain exception word reading deficits in children with developmental dyslexia (e.g., Castles et al., 1999), an alternative explanation may need to be evoked to explain weaknesses in exception word reading in children with poor reading comprehension. Findings from the orthographic choice test are more difficult to interpret. Although the two groups did not differ in performance in the analysis by subjects, there was a significant group difference in the analysis by items. In addition, orthographic choice and exception word reading scores were correlated. This replicates previous studies (e.g. Manis et al., 1996). Further, orthographic choice accounted for variance in exception word reading in the regression analyses, when decoding skills were controlled. However, when earlier exception word reading was controlled for, the contribution of orthographic choice was no longer significant. Taken together, these data suggest that future investigation of the relationship between orthographic knowledge and exception word reading in typically developing children and children classified as poor comprehenders is warranted.

\section{Vocabulary and word recognition skills}

Having demonstrated a relationship between oral vocabulary and the development of word recognition (cf. Bowey, 2001; Keenan \& Betjemann, in press; Nation \& Snowling, 2004), it is important to consider the mechanisms by which this language skill may exert its influence. A distinction between exception words and nonwords was first given prominence in the dual-route model of reading (for its most recent incarnation see Coltheart, Rastle, 
Perry, Langdon, \& Ziegler, 2001). This model suggests that reading of these two types of item is handled by different routes: direct lexical look-up of orthographic form for exception words, and grapheme-phoneme conversion for nonwords. Although the model includes a semantic component and is therefore broadly compatible with the idea that semantic skills relate to aspects of word recognition skill, the model is not sufficiently specified to predict the relationship between vocabulary and exception word reading that was found here. Also, it is important to note that the dual-route approach is primarily a model of skilled reading, and has not been used to simulate reading development.

If we consider how oral vocabulary might play a role in learning to read, the nature of the relationship may plausibly be indirect or direct. As noted in the introduction, oral vocabulary may influence word-level reading indirectly via phonology (Metsala \& Walley, 1998). It may be that children with large oral vocabularies develop more fine-grained or wellorganized phonological representations, which in turn promote the establishment of stronger mappings between phonology and orthography, thus facilitating the development of visual word recognition skills. However, given poor comprehenders' well-developed phonological skills (e.g., Nation et al., 2004, and the present study), this is unlikely to offer a complete explanation of the relationship between vocabulary and word reading.

Another possibility is that vocabulary and word recognition skills are related indirectly via a child's ability to learn the associations between phonological and orthographic stimuli. It seems conceivable that since exception words cannot be decoded easily due to their inconsistent spelling-sound mappings, paired associate learning might provide a particularly useful strategy for their acquisition. In line with this suggestion, Windfuhr and Snowling (2001) found that performance in a visual-verbal (abstract objectnonword) paired associate learning task was related to word reading skills. However, the more specific relationship between paired associate learning and exception word reading has 
yet to be investigated. Laing and Hulme (1999) observed a correlation between a child's knowledge of a word's meaning and their ability to associate it with an orthographic form. Further experiments could examine whether the link between vocabulary and word recognition skills is mediated by paired associate learning, and whether deficits observed in the poor comprehender group could be attributed to this cause.

An alternative explanation for the link between vocabulary and exception word reading is that meaning-based information has a direct influence in the word recognition process itself, and that this influence is emphasized for exception words. According to Share's (1995) self-teaching hypothesis, partial decoding in combination with top-down support from oral vocabulary provides children with a method to read new visual forms. For example, an attempt to decode an exception word like flood based on regular graphemephoneme correspondences will result in the pronunciation/flud/ (i.e. to rhyme with food). However, a child with good vocabulary will have an advantage over a child with weak vocabulary in two respects: first, the child may know that there is a word, flood, that is phonologically close to /flud/; second, the child may be reasonably confident that /flud/ is not a real word, and therefore be willing to seek a phonologically close form rather than a exact match of the regular pronunciation. Thus, for the child who is still learning to read, top-down support can be drawn on to facilitate word recognition in an explicit manner.

Another direct mechanism is specified by the triangle model (e.g., Harm \& Seidenberg, 2004; Plaut et al., 1996). In the model meaning-based information is acquired via statistical learning mechanisms extracting regularities across the vocabulary to which the network has been exposed. This semantic information then contributes directly and implicitly to the pronunciation of all words, regardless of their regularity or familiarity. Assuming that oral vocabulary provides a reasonable proxy for the skills that contribute to the semantic 
pathway, our results are consistent with the triangle model in demonstrating a clear relationship between oral vocabulary and aspects of word reading behavior.

Although there are limitations in the psychological validity of the learning mechanisms employed by current incarnations of the triangle model (Nation, in press; Powell, Plaut, \& Funnell, 2006), it nevertheless provides an opportunity to reveal factors that have the power to encourage developmental change. Factors such as the nature of representation, the strength of learning and generalization, and the lexical characteristics of the reading environment can all be manipulated independently and in interaction, and their effects on word recognition development assessed via simulations. Predictions from these simulations can then be compared with experimental data from children. So far, phonology and semantics are the only language factors that have been incorporated into simulations of the triangle model. It is worth noting that the manner in which semantic information is instantiated in the triangle model lacks psychological validity, an issue that should be addressed in future models. Also, Bishop and Snowling (2004) have proposed that the model should be extended to include the influence of grammar and discourse level context on reading. This highlights the need for future research to address the role of other language factors such as context, and consider how they interact with phonological skills and orthographic knowledge.

Vocabulary, reading comprehension and exception word reading

The finding that oral vocabulary is related to reading comprehension level could be interpreted in a number of ways. The extent of a child's oral vocabulary could limit comprehension if a text that they are trying to read contains words that they do not know. On the other hand, as reading provides an opportunity for learning new words, reading comprehension could place a limit on vocabulary development (e.g., Beck et al., 1982). A third possibility is that the relationship is mediated by shared processes, for example, the 
ability to use context (Sternberg \& Powell, 1983). These mechanisms do not seem to be mutually exclusive; each could play a role in development. However, the design of the current study does not allow for clear causal conclusions to be drawn. As reading comprehension was not assessed at time 2 , earlier vocabulary could not be used to predict improvement in this skill. Nevertheless, it is interesting to note that vocabulary and reading comprehension are highly correlated, and that vocabulary accounted for unique variance in reading comprehension. In addition, reading comprehension at time 1 explained $11 \%$ of the variance in vocabulary at time 2 , even after the autoregressor effect of vocabulary measured at time 1 was controlled $(F=6.61, p<.05)$. These data suggest that the relationship between vocabulary and reading comprehension is likely to be interactive and reciprocal.

Our findings revealed a relationship between vocabulary knowledge and reading comprehension, and between exception word reading and reading comprehension. Also, vocabulary knowledge accounted for significant additional variance in reading comprehension when exception word reading was controlled, whereas exception word reading did not account for variance in reading comprehension when vocabulary was controlled. This is consistent with the suggestion that underlying vocabulary knowledge drives the association between reading comprehension and exception word reading (Keenan \& Betjemann, in press; Nation \& Snowling, 1998). Our study has provided evidence for vocabulary playing an important role in both reading comprehension and exception word reading, but clearly additional data from longitudinal studies and training studies are needed to explore causal mechanisms. It is also important to note that not all poor comprehenders exhibited a vocabulary deficit. Other studies have similarly failed to observe semantic weaknesses across all poor comprehenders (Cain, Oakhill, \& Lemmon, 2004). Therefore, it is not the case that reading comprehension or exception word reading difficulties are always accompanied by vocabulary weakness. 
In summary, the findings of this study suggest that vocabulary is related to some aspects of reading and not others. Our observation of an intimate relationship between vocabulary and reading comprehension is consistent with many previous studies; more surprising is our finding that vocabulary plays a role in word recognition, especially when the word to be read is inconsistent in spelling-sound correspondence. However, much remains to be learned about how vocabulary is related to word recognition. As a cautionary note, we do not intend to imply clear causal relations in this paper. Future studies should attempt to examine potential causal relationships (e.g. with training studies). In addition, a significant area of interest is whether the relationship is direct or indirect, and how it interacts with other aspects of lexical processing including phonological and orthographic processing through development. 


\section{References}

Beck, I. L., Perfetti, C. A., \& McKeown, M. G. (1982). Effects of long-term vocabulary instruction on lexical access and reading-comprehension. Journal of Educational Psychology, 74, 506-521.

Bishop, D. V., \& Snowling, M. J. (2004). Developmental dyslexia and specific language impairment: Same or different? Psychological Bulletin, 130, 858-886.

Bowey, J. A. (2001). Does poor exception word reading reflect vocabulary deficits? Australian Journal of Psychology, 53, 177-177.

Bowyer-Crane, C. A., \& Snowling, M. J. (2005). Assessing children's inference generation: What do tests of reading comprehension measure? British Journal of Educational Psychology, 75, 189-201.

Brady, S., \& Shankweiler, D. (1991). Phonological processes in literacy: A tribute to Isabelle Y. Liberman. Hillsdale, NJ: Erlbaum.

Byrne, B. (1998). The foundation of literacy: the child's acquisition of the alphabetic principle. Hove, East Sussex: Psychology Press.

Byrne, B., Freebody, P., \& Gates, A. (1992). Longitudinal data on the relations of word-reading strategies to comprehension, reading time, and phonemic awareness. Reading Research Quarterly, 27, 140-151.

Cain, K., Oakhill, J., \& Bryant, P. (2000). Phonological skills and comprehension failure: A test of the phonological processing deficit hypothesis. Reading and Writing, 13, 3156. 
Cain, K., Oakhill, J., \& Bryant, P. (2004). Children's reading comprehension ability: Concurrent prediction by working memory, verbal ability, and component skills. Journal of Educational Psychology, 96, 31-42.

Cain, K., Oakhill, J., \& Lemmon, K. (2004). Individual differences in the inference of word meanings from context: The influence of reading comprehension, vocabulary knowledge, and memory capacity. Journal of Educational Psychology, 96, 671-681.

Castles, A., Datta, H., Gayan, J., \& Olson, R. K. (1999). Varieties of developmental reading disorder: Genetic and environmental influences. Journal of Experimental Child Psychology, 72, 73-94.

Castles, A., \& Nation, K. (2006). How does orthographic learning happen? In S. Andrews (Ed.), From inkmarks to ideas: Challenges and controversies about word recognition and reading. Hove, East Sussex: Psychology Press.

Catts, H. W., Adlof, S. M., \& Weismer, S. E. (2006). Language deficits in poor comprehenders: A case for the simple view of reading. Journal of Speech, Language, and Hearing Research, 49, 278-293.

Coltheart, M., \& Leahy, J. (1996). Assessment of lexical and nonlexical reading abilities in children: Some normative data. Australian Journal of Psychology, 48, 136-140.

Coltheart, M., Rastle, K., Perry, C., Langdon, R., \& Ziegler, J. (2001). DRC: A dual route cascaded model of visual word recognition and reading aloud. Psychological Review, $108,204-256$.

Cunningham, A. E., Perry, K. E., \& Stanovich, K. E. (2001). Converging evidence for the concept of orthographic processing. Reading and Writing: An Interdisciplinary Journal, $14,549-568$. 
Cunningham, A. E., \& Stanovich, K. E. (1993). Childrens Literacy Environments and Early Word Recognition Subskills. Reading and Writing, 5(2), 193-204.

Goswami, U., \& Bryant, P. (1990). Phonological skills and learning to read. Hove, East Sussex: Lawrence Erlbaum.

Griffiths, Y. M., \& Snowling, M. J. (2002). Predictors of exception word and nonword reading in dyslexic children: The severity hypothesis. Journal of Educational Psychology, 94, 34-43.

Harm, M., \& Seidenberg, M. (1999). Phonology, reading acquisition, and dyslexia: Insights from connectionist models. Psychological Review, 106(3), 491-528.

Harm, M., \& Seidenberg, M. S. (2004). Computing the meanings of words in reading: Cooperative division of labor between visual and phonological processes. Psychological Review, 111, 662-720.

Keenan, J. M., \& Betjemann, R. S. (in press). Comprehension of single words: The role of semantics in word identification and reading disability. In E. Grigorenko \& A. Naples (Eds.), Single-word reading: Behavioral and biological perspectives. Mahwah, NJ: Erlbaum.

Laing, E., \& Hulme, C. (1999). Phonological and semantic processes influence beginning readers' ability to learn to read words. Journal of Experimental Child Psychology, 73, 183-207.

Manis, F. R., Seidenberg, M., Doi, L. M., McBride-Chang, C., \& Petersen, A. (1996). On the bases of two subtypes of developmental dyslexia. Cognition, 58, 157-195.

Masterson, J., Dixon, M., \& Stuart, M. (2002). The Children's Printed Word Database, from http://www.essex.ac.uk/psychology/cpwd/ 
McDougall, S., Hulme, C., Ellis, A., \& Monk, A. (1994). Learning to read: The role of short-term memory and phonological skills. Journal of Experimental Child Psychology, $58,112-133$.

Metsala, J. L., \& Walley, A. C. (1998). Spoken vocabulary growth and the segmental restructuring of lexical representations: Precursors to phonemic awareness and early reading ability. In J. L. Metsala \& L. C. Ehri (Eds.), Word recognition in beginning literacy (pp. 89120). Mahwah, NJ, US: Lawrence Erlbaum Associates.

Nation, K. (2005). Children's reading comprehension difficulties. In M. J. Snowling, C. Hulme \& M. Seidenberg (Eds.), The science of reading: A handbook (pp. 248-265). Oxford: Blackwell.

Nation, K. (in press). Decoding, orthographic learning and the development of visual word recognition. In M. Spivey, K. McRae \& M. Joanisse (Eds.), Cambridge handbook of psycholinguistics.

Nation, K., Clarke, P., Marshall, C. M., \& Durand, M. (2004). Hidden language impairments in children: Parallels between poor reading comprehension and specific language impairment. Journal of Speech, Language, and Hearing Research, 47, 199-211.

Nation, K., \& Snowling, M. J. (1998). Semantic processing and the development of word recognition skills: Evidence from children with reading comprehension difficulties. Journal of Memory and Language, 39, 85-101.

Nation, K., \& Snowling, M. J. (2004). Beyond phonological skills: Broader language skills contribute to the development of reading. Journal of Research in Reading, 27, 342-356.

Neale, M. (1997). Neale Analysis of Reading Ability - Second Revised British Edition. Windsor: NFER. 
Oakhill, J., \& Yuill, N. (1996). Higher order factors in comprehension disability: Processes and remediation. In C. Cornoldi \& J. Oakhill (Eds.), Reading comprehension difficulties (pp. 69-92). Mahwah, NJ: Erlbaum.

Olson, R. K., Forsberg, H., Wise, B., \& Rack, J. (1994). Measurement of word recognition, orthographic and phonological skills. In G. R. Lyon (Ed.), Frames of reference for the assessment of learning disabilities (pp. 243-277). Baltimore, MD: Brookes.

Plaut, D. C., McClelland, J. L., Seidenberg, M., \& Patterson, K. (1996). Understanding normal and impaired word reading: Computational principles in quasi-regular domains. Psychological Review, 103, 56-115.

Powell, D., Plaut, D. C., \& Funnell, E. (2006). Does the PMSP connectionist model of single word reading learn to read in the same way as a child? Journal of Research in Reading, 29, 229-250.

Seidenberg, M., \& McClelland, J. L. (1989). A distributed, developmental model of word recognition. Psychological Review, 96, 523-568.

Share, D. L. (1995). Phonological recoding and self-teaching: Aine qua non of reading acquisition. Cognition, 55, 151-218.

Sternberg, R. J., \& Powell, J. S. (1983). Comprehending verbal comprehension. American Psychologist, 38, 878-893.

Torgesen, J., Wagner, R., \& Rashotte, C. (1999). Test of Word Reading Efficiency. Austin, TX: Pro-Ed.

Vellutino, F.R., Scanlon, D.M., \& Tanzman, M. (1994). Components of reading ability. In G.R. Lyon (Ed.), Frames of reference for the assessment of learning disabilities (pp. 279-329). Baltimore, MD: Brookes. 
Walley, A. C., Metsala, J. L., \& Garlock, V. M. (2003). Spoken vocabulary growth: Its role in the development of phoneme awareness and early reading ability. Reading and Writing: An Interdisciplinary Journal, 16, 5-20.

Wechsler, D. (1999). Wechsler Abbreviated Scale of Intelligence. London: The Psychological Corporation.

Wiig, E. H., \& Secord, W. (1992). Test of Word Knowledge. US: The Psychological Corporation.

Windfuhr, K. L., \& Snowling, M. J. (2001). The relationship between paired associate learning and phonological skills in normally developing readers. Journal of Experimental Child Psychology, 80, 160-173. 
Author notes

Jessie Ricketts, Kate Nation, D.V.M. Bishop, University of Oxford. We would like to thank The Economic and Social Research Council for a studentship awarded to the first author and grant awarded to the second and third authors. The third author is supported by The Wellcome Trust.

Correspondence should be addressed to Jessie Ricketts, Department of Experimental Psychology, University of Oxford, South Parks Road, Oxford, OX1 3UD, UK. Email: jessie.ricketts@psy.ox.ac.uk; Web: www.psy.ox.ac.uk/lcd, www.psy.ox.ac.uk/oscci 


\section{Footnotes}

${ }^{1}$ Due to ceiling effects on a number of regular items, Chronbach's $\alpha$ for the regular word list was recalculated on the basis of 26 items.

${ }^{2}$ For a full set of the words and nonwords used to assess component reading skills, please contact the corresponding author.

${ }^{3}$ Note that this reliability value is low. McDougall et al. (1994) did not report reliability for this measure so a comparison is not possible.

${ }^{4}$ For a full set of items used in the ART task, please contact the corresponding author.

${ }^{5}$ Time 2 chronological age and time 1 nonverbal reasoning scores did not correlate with time 2 exception word reading supporting their exclusion from analyses. Time 1 chronological age did correlate with time 2 exception word reading but when this variable was included the pattern of results for all analyses was almost identical. 
Table 1.

Mean chronological age and performance of whole sample $(N=81)$

\begin{tabular}{llll}
\hline & $M$ & $S D$ & Range \\
\hline Chronological age $^{1}$ & 9.21 & 0.29 & $8.67-9.75$ \\
TOWRE Phonemic decoding $^{2}$ & 105.02 & 12.16 & $85-139$ \\
WASI Matrices $^{3}$ & 52.46 & 7.91 & $27-66$ \\
WASI Vocabulary $^{3}$ & 49.51 & 9.65 & $27-75$ \\
NARA-II Reading comprehension $^{2}$ & 91.37 & 8.89 & $75-121$ \\
NARA-II Text reading accuracy $^{2}$ & 100.74 & 9.82 & $84-122$ \\
Regular words $^{4}$ & 0.90 & 0.10 & $0.60-1.00$ \\
Exception words $^{4}$ & 0.68 & 0.12 & $0.37-0.97$ \\
Nonwords $^{4}$ & 0.72 & 0.20 & $0.17-1.00$
\end{tabular}

Notes. ${ }^{1}$ In years; ${ }^{2}$ Standard scores, $M=100, S D=15 ;{ }^{3} \mathrm{~T}$ scores, $M=50, S D=10$;

${ }^{4}$ Proportion correct 
Table 2.

Mean performance of poor and skilled comprehension groups on selection and other time 1 measures

\begin{tabular}{lllll}
\hline Poor & Skilled & PC vs. SC & Estimated \\
Comprehenders & Comprehenders & $F(1,28)$ & effect size \\
& & & \\
$(\mathrm{PC}, \mathrm{N}=15)$ & $(\mathrm{SC}, \mathrm{N}=15)$ & \\
\hline$M$ & SD & $\mathrm{M}$ & $\mathrm{SD}$
\end{tabular}

Selection measures

Chronological age ${ }^{1}$

$9.21 \quad 0.30$

9.26

0.28

0.22

0.01

TOWRE decoding ${ }^{2}$

$107.67 \quad 13.11$

$108.27 \quad 9.68$

0.02

0.00

WASI Matrices ${ }^{3}$

$52.33 \quad 5.02$

52.33

4.29

0.00

0.00

NARA-II Reading

$81.93 \quad 2.69$

$103.13 \quad 4.88$

$217.14^{* *}$

0.89

comprehension $^{2}$

Other time 1 measures

$\begin{array}{lcccccc}\text { NARA-II Text reading } & 99.27 & 9.43 & 108.07 & 8.18 & 7.45^{*} & 0.21 \\ \text { accuracy }^{2} & & & & & & \\ \text { WASI Vocab }^{3} & 42.80 & 9.09 & 56.67 & 5.39 & 25.82^{* *} & 0.48 \\ \text { Regular words }^{4} & 0.88 & 0.12 & 0.94 & 0.06 & 2.56 & 0.08 \\ \text { Exception words }^{4} & 0.64 & 0.11 & 0.78 & 0.08 & 14.31^{* *} & 0.34 \\ \text { Nonwords }^{4} & 0.76 & 0.16 & 0.78 & 0.17 & 0.06 & 0.00\end{array}$

Notes. ${ }^{*} p<0.05 ; * * p \leq 0.001 ;{ }^{1}$ In years; ${ }^{2}$ Standard scores, $M=100, S D=15 ;{ }^{3} \mathrm{~T}$ scores, $M=$ $50, S D=10 ;{ }^{4}$ Proportion correct 
Table 3.

Mean performance of poor and skilled comprehension groups on time 2 measures

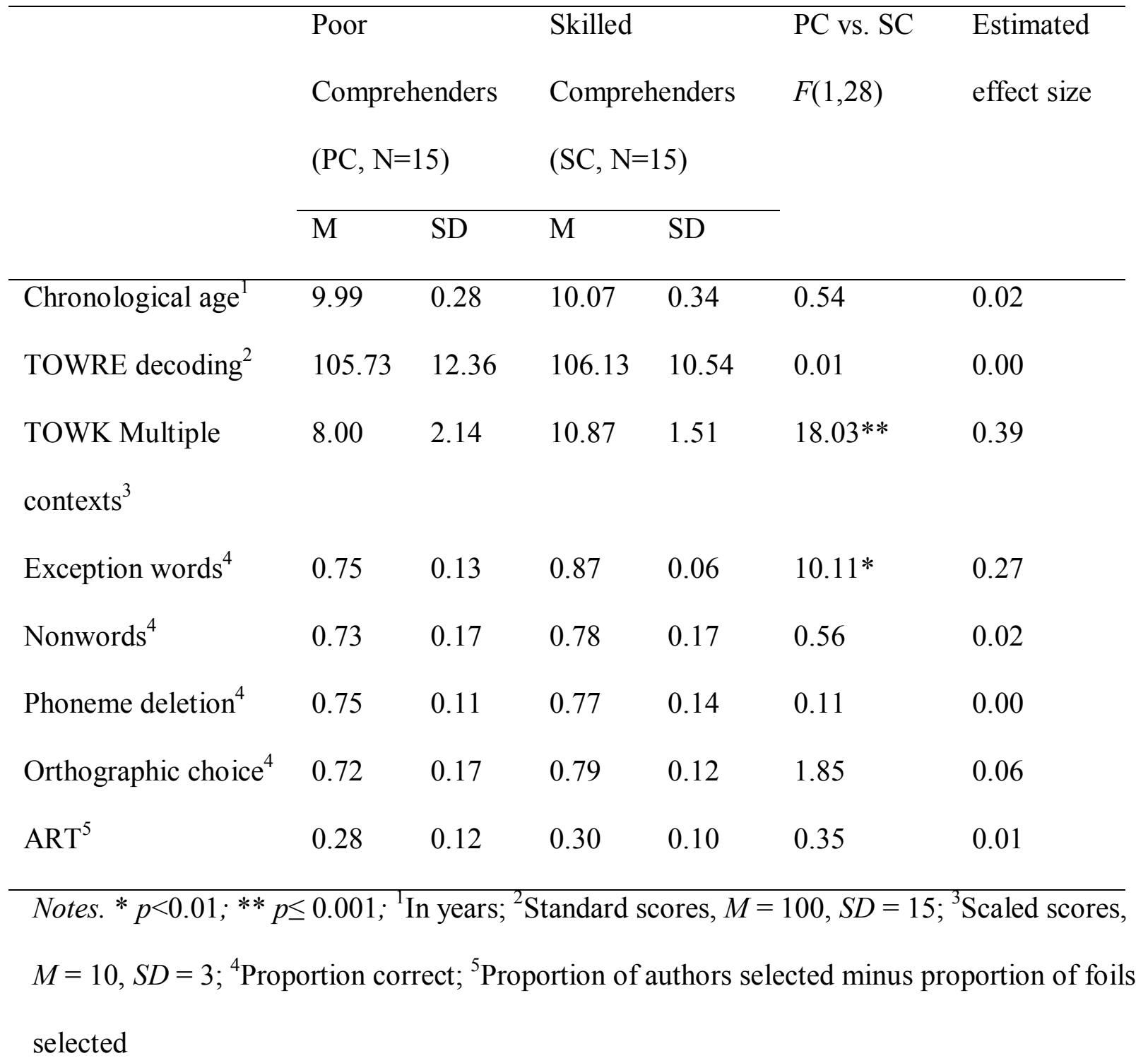


n

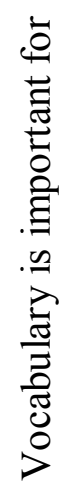

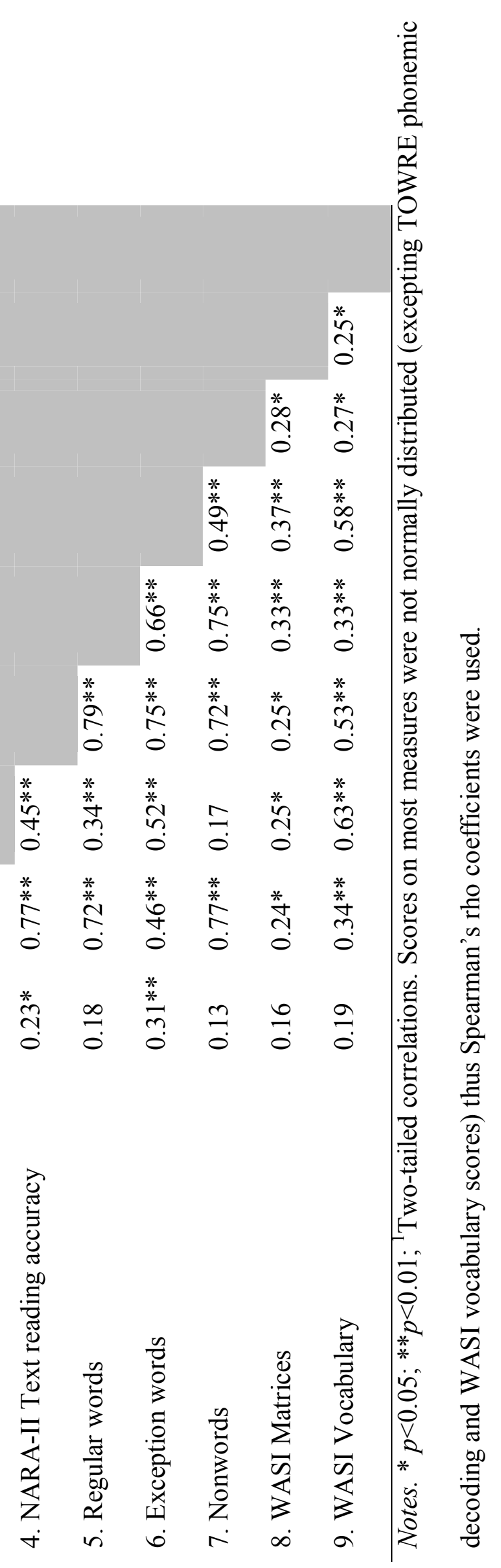


Table 5.

Hierarchical regressions with whole sample predicting reading comprehension and text reading accuracy from the $N A R A-I I$

\begin{tabular}{|c|c|c|c|c|}
\hline Step & Variable added & $\Delta R^{2}$ & $p$ & Final $\beta$ \\
\hline & & \multicolumn{3}{|c|}{ Reading comprehension } \\
\hline 1 & Chronological age & .046 & .05 & .050 \\
\hline 2 & WASI matrices & .037 & .08 & -.015 \\
\hline 3 & Decoding composite & .030 & .11 & -.163 \\
\hline 4 & Regular word reading & .053 & $<.05$ & .158 \\
\hline 5 & Exception word reading & .152 & $<.001$ & .238 \\
\hline 6 & Vocabulary & .178 & $<.001$ & $.515 * * *$ \\
\hline 5 & Vocabulary & .307 & $<.001$ & $.515^{* * *}$ \\
\hline \multirow[t]{2}{*}{6} & Exception word reading & .023 & .07 & .238 \\
\hline & & \multicolumn{3}{|c|}{ Text reading accuracy } \\
\hline 1 & Chronological age & .030 & .12 & -.010 \\
\hline 2 & WASI matrices & .063 & $<.05$ & -.107 \\
\hline 3 & Decoding composite & .538 & $<.001$ & $.532 * * *$ \\
\hline 4 & Regular word reading & .026 & $<.05$ & .036 \\
\hline 5 & Exception word reading & .123 & $<.001$ & $.419 * * *$ \\
\hline 6 & Vocabulary & .009 & .08 & .118 \\
\hline 5 & Vocabulary & .061 & $<.001$ & .118 \\
\hline 6 & Exception word reading & .071 & $<.001$ & $.419 * * *$ \\
\hline
\end{tabular}

Notes. $p$ values refer to the significance level for variance explained by the variable as it is entered into the model. Final (standardized) $\beta$ values correspond to the variable in the complete model with all variables included. $* p<.05 ; * * p<.01 ; * * *<.001$ 
Table 6.

Hierarchical regressions with whole sample predicting nonword reading, regular word reading and exception word reading

\begin{tabular}{|c|c|c|c|c|}
\hline Step & Variable added & $\Delta R^{2}$ & $p$ & Final $\beta$ \\
\hline & & \multicolumn{3}{|c|}{ Exception word reading } \\
\hline 1 & Chronological age & .074 & 0.01 & .111 \\
\hline 2 & WASI matrices & .148 & $<0.001$ & $.168 *$ \\
\hline 3 & Decoding composite & .176 & $<0.001$ & .064 \\
\hline 4 & Regular word reading & .088 & 0.001 & $.400 * *$ \\
\hline \multirow[t]{2}{*}{5} & Vocabulary & .109 & $<0.001$ & $.359 * * *$ \\
\hline & & \multicolumn{3}{|c|}{ Regular word reading } \\
\hline 1 & Chronological age & .036 & 0.09 & .045 \\
\hline 2 & WASI matrices & .085 & $<0.01$ & -.004 \\
\hline 3 & Decoding composite & .473 & $<0.001$ & $.585^{* * *}$ \\
\hline 4 & Exception word reading & .059 & 0.001 & $.342 * *$ \\
\hline \multirow[t]{2}{*}{5} & Vocabulary & .002 & 0.56 & -.049 \\
\hline & & \multicolumn{3}{|c|}{ Nonword reading (decoding composite) } \\
\hline 1 & Chronological age & .010 & 0.37 & -.060 \\
\hline 2 & WASI matrices & .089 & $<0.01$ & .064 \\
\hline 3 & Regular word reading & .484 & $<0.001$ & $.698 * * *$ \\
\hline 4 & Exception word reading & .004 & 0.41 & .065 \\
\hline 5 & Vocabulary & .001 & 0.73 & .032 \\
\hline
\end{tabular}

Notes. $p$ values refer to the significance level for variance explained by the variable as it is entered into the model. Final (standardized) $\beta$ values correspond to the variable in the complete model with all variables included. $* p<.05 ; * * p<.01 ; * * * p<.001$ 
Table 7.

Hierarchical regression with poor and skilled comprehenders predicting time 2 exception word reading from vocabulary

\begin{tabular}{|c|c|c|c|c|c|}
\hline Model & Step & Variable added & $\Delta R^{2}$ & $p$ & Final $\beta$ \\
\hline \multirow[t]{2}{*}{1} & 1 & Decoding composite ( $\mathrm{t} 1$ and $\mathrm{t} 2$ ) & .188 & $<0.05$ & $.359 *$ \\
\hline & 2 & Vocabulary (t2) & .257 & $<0.01$ & $.512 * *$ \\
\hline \multirow[t]{2}{*}{2} & 1 & Decoding composite ( $\mathrm{t} 1$ and $\mathrm{t} 2$ ) & .188 & $<0.05$ & $.274^{*}$ \\
\hline & 2 & Vocabulary (t1) & .439 & $<0.001$ & $.682 * * *$ \\
\hline \multirow[t]{3}{*}{3} & 1 & Decoding composite ( $\mathrm{t} 1$ and $\mathrm{t} 2$ ) & .188 & $<0.05$ & .117 \\
\hline & 2 & Exception word reading $(\mathrm{t} 1)$ & .503 & $<0.001$ & $.739 * * *$ \\
\hline & 3 & Vocabulary (t2) & .002 & 0.71 & .056 \\
\hline \multirow[t]{3}{*}{4} & 1 & Decoding composite (t1 and $\mathrm{t} 2$ ) & .188 & $<0.05$ & .138 \\
\hline & 2 & Exception word reading $(\mathrm{t} 1)$ & .503 & $<0.001$ & $.533 * *$ \\
\hline & 3 & Vocabulary (t1) & .040 & 0.06 & .310 \\
\hline
\end{tabular}

Notes. $p$ values refer to the significance level for variance explained by the variable as it is entered into the model. Final (standardized) $\beta$ values correspond to the variable in the complete model with all variables included. $* p<.05 ; * * p<.01 ; * * * p<.001$ 
Table 8.

Hierarchical regression with poor and skilled comprehenders predicting time 2 exception word reading from reading-related skills controlling for decoding

\begin{tabular}{llllll}
\hline Model & Step & Variable added & $\Delta R^{2}$ & $p$ & Final $\beta$ \\
\hline 1 & 1 & Decoding composite (t1 and $\mathrm{t} 2)$ & .188 & $<0.05$ & .432 \\
& 2 & Phoneme deletion (t2) & .000 & 0.99 & .003 \\
\hline 2 & 1 & Decoding composite ( $\mathrm{t} 1$ and $\mathrm{t} 2)$ & .188 & $<0.05$ & $.428^{*}$ \\
& 2 & Print exposure (ART, $\mathrm{t} 2)$ & .001 & 0.86 & .031 \\
& & & & & \\
\hline 3 & 1 & Decoding composite (t1 and $\mathrm{t} 2)$ & .188 & $<0.05$ & -.033 \\
& 2 & Orthographic choice (t2) & .171 & 0.01 & $.624^{*}$ \\
\hline 4 & 1 & Decoding composite (t1 and $\mathrm{t} 2)$ & .188 & $<0.05$ & -.075 \\
& 2 & Exception word reading (t1) & .503 & $<0.001$ & $.708^{* * *}$ \\
& 3 & Orthographic choice (t2) & .031 & 0.10 & .285
\end{tabular}

Notes. $p$ values refer to the significance level for variance explained by the variable as it is entered into the model. Final (standardized) $\beta$ values correspond to the variable in the complete model with all variables included. ${ }^{*} p<.05 ; * * p<.01 ; * * * p<.001$ 


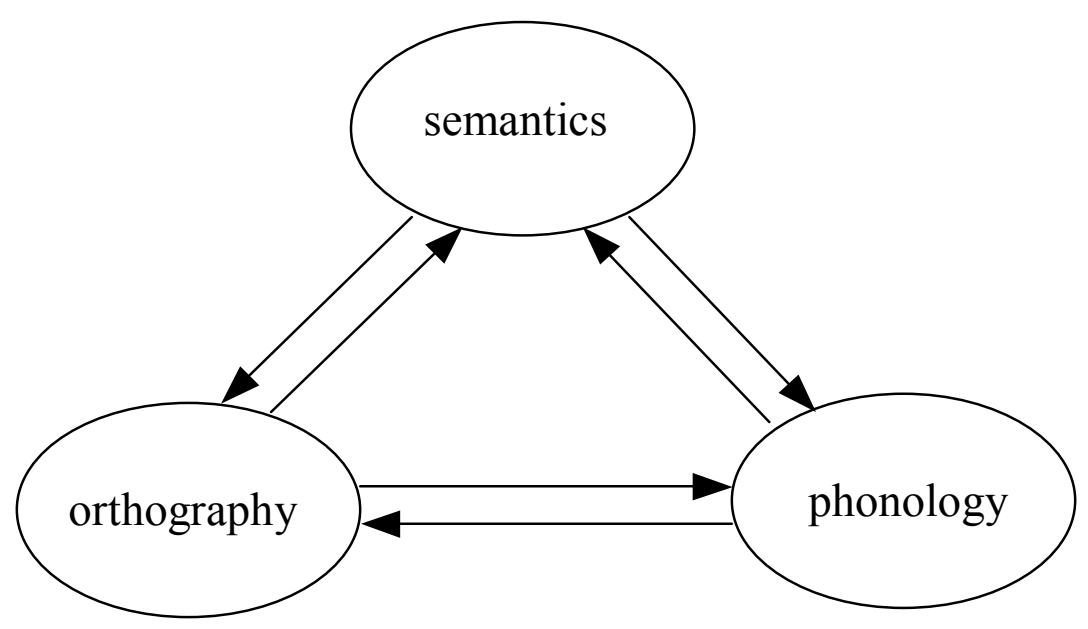

Figure 1. The triangle model, after Seidenberg and McClelland (1989), Plaut et al. (1996). 